\title{
Estudo anatômico de folha e caule de Elephantopus mollis Kunth (Asteraceae)
}

\author{
Cláudia Bonissoni Empinotti, Márcia do Rocio Duarte* \\ Laboratório de Farmacognosia, Departamento de Farmácia, Universidade Federal do Paraná, \\ Av. Pref. Lothário Meissner 632, 80210-170 Curitiba-PR, Brasil
}

\begin{abstract}
RESUMO: Conhecida comumente como erva-de-colégio, erva-grossa e sussuaiá, Elephantopus mollis Kunth (Asteraceae) é uma espécie herbácea perene, de base sublenhosa, ramos curtos e flores arroxeadas. Suas folhas são empregadas como emoliente, resolutivo, sudorífico e no tratamento de bronquite, tosse e gripe na medicina popular. $\mathrm{O}$ objetivo deste trabalho foi estudar caracteres anatômicos foliares e caulinares, a fim de fornecer subsídios aplicáveis à identificação da planta medicinal. Folhas adultas e fragmentos de caules foram fixados, seccionados e corados com azul de astra/fucsina básica ou com azul de toluidina. Testes microquímicos e análise ultraestrutural de superfície foram também executados. A folha possui epiderme uniestratificada, recoberta por cutícula estriada e, em vista frontal, tem células com contorno ondulado. Ocorrem tricomas tectores e glandulares. Os primeiros são eretos, pluricelulares e unisseriados. Os tricomas glandulares são capitados e bisseriados. O mesofilo é dorsiventral e a nervura central é percorrida por feixes vasculares colaterais dispostos em arco aberto. O caule, em estrutura secundária inicial, possui epiderme unisseriada com cutícula estriada e tricomas semelhantes aos da folha. No córtex, observam-se colênquima anelar alternado com clorênquima e endoderme com estrias de Caspary. Calotas esclerenquimáticas apõem-se ao floema. Este é formado pelo câmbio vascular em direção à periferia e o xilema é gerado de modo centrípeto. A medula é parenquimática. Pequenos cristais de oxalato de cálcio estão presentes na folha e no caule.
\end{abstract}

Unitermos: Elephantopus mollis, Asteraceae, cristais, endoderme, tricoma glandular, tricoma tector.

\begin{abstract}
Anatomical study of the leaf and stem of Elephantopus mollis Kunth (Asteraceae)". Commonly known as erva-de-colégio in Portuguese, Elephantopus mollis Kunth (Asteraceae) is a perennial herb, with slightly lignified base, short branches and purple flowers. Its leaves are used as emollient, vulnerary and diaphoretic, and to treat bronchitis, coughs and influenza in folk medicine. The aim of this work was to study leaf and stem anatomical characters, in order to expand the knowledge for this medicinal plant identification. Adult leaves and stem fragments were fixed, sectioned and stained either with astra blue/basic fuchsine or toluidine blue. Microchemical essays and scanning electron analysis were also carried out. The leaf has wavy-contoured cells in surface view, forming a single layer and coated with striate cuticle. Nonglandular and glandular trichomes occur. The former is erect, multicellular and uniseriate. The glandular ones are capitate and biseriate. The mesophyll is dorsiventral and the midrib is traversed by collateral vascular bundles arranged in open arc. The stem, in initial secondary growth, has uniseriate epidermis coated with striate cuticle and trichomes similar to the leaf. In the cortex, annular collenchyma alternates with chlorenchyma and an endodermis with Casparian strips is found. Sclerenchymatic caps adjoin the phloem, which is formed outwards by the vascular cambia, while the xylem is produced inwards. The pith is parenchymatic. Small calcium oxalate crystals are present in the leaf and stem.
\end{abstract}

Keywords: Elephantopus mollis, Asteraceae, crystals, endodermis, glandular trichome, nonglandular trichome.

\section{INTRODUÇÃO}

O gênero Elephantopus pertence à família Asteraceae, à subfamília Latucoideae e à tribo Vernonieae, a qual é representada nos dois hemisférios por um total aproximado de 51 gêneros e 1200 espécies
(Barroso, 1991).Elephantopus mollis Kunth (Figuras 1A, 1B) é uma planta herbácea perene, de base sublenhosa e ramos muito curtos, nativa do continente americano e encontrada em todo o Brasil (Cabrera \& Klein, 1980; Lorenzi \& Matos, 2002). Os caules são cinzentos e pubescentes, e as folhas são ásperas, obovadas, sub- 
obtusas no ápice, longamente atenuadas na base, crenado-serreadas nos bordos, pubescentes na face adaxial e pilosas na abaxial. As flores são arroxeadas, dispostas em capítulos terminais e axilares, protegidos por brácteas (Cabrera \& Klein, 1980; Takeda \& Farago, 2001; Lorenzi \& Matos, 2002).

E. mollis é conhecida comumente como ervade-colégio, erva-grossa, fumo-bravo, língua-de-vaca, pé-de-elefante e sussuaiá (Cabrera \& Klein, 1980; Corrêa, 1984; Brüning, 2000; Takeda \& Farago, 2001; Lorenzi \& Matos, 2002). Na medicina popular, as folhas são usadas como emoliente, resolutivo, sudorífico, no combate aos cálculos urinários e para tratar bronquite, tosse e gripe, principalmente na forma de chá por infusão ou decocção (Cabrera \& Klein, 1980; Corrêa, 1984; Takeda \& Farago, 2001; Lorenzi \& Matos, 2002; Biavatti et al., 2007). Estudos fitoquímicos indicaram a presença de flavonóides, triterpenóides e lactonas sesquiterpênicas (Banerjee et al., 1986; But et al., 1996; Lorenzi \& Matos, 2002), algumas das quais com propriedades antitumoral (Lee et al., 1975, 1980) e leishmanicida (Fuchino et al., 2001). O extrato bruto revelou efeitos hepatoprotetor (Lin et al., 1991; Lin et al.1995) e antiinflamatório contra artrite aguda e crônica (Tsai \& Lin, 1999).

Em razão da escassez de estudos morfológicos sobre essa espécie medicinal, este trabalho teve como objetivo estudar a anatomia foliar e caulinar de Elephantopus mollis Kunth (Asteraceae), a fim de fornecer informações anatômicas para a identificação da mesma.

\section{MATERIAL E MÉTODOS}

\section{Material vegetal}

O material botânico foi coletado em Palotina, município do oeste do Paraná, nas coordenadas aproximadas de $24^{\circ} 17^{\prime}$ de latitude e $53^{\circ} 40^{\prime}$ ' de longitude, numa altitude de $290 \mathrm{~m}$, em fevereiro e março de 2005 . A exsicata foi depositada no Herbário do Museu Botânico Municipal de Curitiba-PR, sob o registro MBM 301455.

\section{Metodologia}

Folhas adultas e fragmentos caulinares, coletados a partir de $5 \mathrm{~cm}$ do ápice, foram fixados em FAA 50 (Johansen, 1940) e estocados em etanol a 50\% (Berlyn \& Miksche, 1976). Lâminas semipermanentes foram obtidas a partir de secções transversais e longitudinais, à mão livre. Para o preparo do laminário permanente o material foi desidratado em série etanólica crescente, emblocado em glicol-metacrilato (Leica Historesin ${ }^{\circledR}$ ) e seccionado no micrótomo rotativo Olympus CUT 4055. Os cortes foram submetidos à dupla coloração azul de astra/fucsina básica (Roeser, 1972) ou corados com azul de toluidina (O’Brien et al., 1964).

Testes microquímicos foram também executados com as soluções de Sudan III para evidenciar substâncias lipofílicas (Sass, 1951), lugol para amido (Berlyn \& Miksche, 1976), cloreto férrico para compostos fenólicos (Johansen, 1940), floroglucina clorídrica para lignina (Foster, 1949) e ácido sulfúrico para cristais de oxalato de cálcio (Oliveira \& Akisue, 1997). Realizaram-se fotomicrografias no microscópio fotônico Olympus BX-40, acoplado à unidade de controle PM-20.

A análise ultra-estrutural de superfície (Souza, 1998) foi efetuada em lâmina foliar e caule de material fixado em Carnoy (Kraus \& Arduin, 1997) e desidratado em série etanólica crescente e pelo ponto crítico de $\mathrm{CO}_{2}$ no equipamento Bal-Tec CPD-030. As amostras foram aderidas a suporte metálico e examinadas em baixo vácuo no microscópio eletrônico de varredura JEOL JSM-6360LV.

\section{RESULTADOS}

\section{Anatomia foliar}

Na lâmina foliar, a epiderme consiste de uma única camada de células (Figura 2E), com paredes anticlinais delgadas, comparativamente mais onduladas na face abaxial, em vista frontal (Figuras 1C-F). A cutícula é delgada (Figura 2E) e estriada (Figuras 1D, $1 \mathrm{~F}$ ), e estômatos anomocíticos e anisocíticos (Figuras $1 \mathrm{D}, 1 \mathrm{~F})$ são encontrados em maior número na face abaxial, inserindo-se praticamente no mesmo nível que as células adjacentes (Figura 2E).

Tricomas tectores e glandulares (Figuras 1C-E, 2A, 2B, 2E) são observados nas duas superfícies foliares, com maior freqüência na abaxial. Os primeiros (Figuras 1C, 1E, 2A) são eretos, pluricelulares e unisseriados, constituindo-se de uma base eventualmente alargada e com cerca de duas ou três células curtas e de uma célula terminal longa e afilada. Apresentam paredes espessadas revestidas por cutícula lisa e a porção basal é ladeada por células dispostas em roseta levemente acima do nível da epiderme. Os tricomas glandulares (Figuras 1C-E, 2B, 2E) são capitados, pluricelulares e bisseriados, de formato ovóide, localizados em leve depressão epidérmica (Figura 2E).

$\mathrm{O}$ mesofilo (Figura 2E) tem organização dorsiventral, consistindo de clorênquimas pouco diferenciados. O parênquima paliçádico compõe-se de uma ou duas camadas de células curtas e o parênquima esponjoso é multiestratificado, correspondendo a aproximadamente $70 \%$ da altura do mesofilo. Além de cloroplastos, os clorênquimas apresentam alguns amiloplastos e pequena quantidade de substâncias fenólicas. Mergulhados no parênquima esponjoso, encontram-se feixes vasculares colaterais, envoltos por bainha parenquimática (Figura 2E). Os feixes de médio 
porte mostram calotas esclerenquimáticas apostas ao floema.

A nervura central (Figura 2C) exibe formato biconvexo em secção transversal, com ângulo obtuso, tendendo a ser achatadajuntoà face adaxial. Oparênquima paliçádico acompanha parcialmente a nervura, sendo gradativamente substituído por colênquima. Este se revela anelar a angular e se compõe de cerca de sete estratos na superfície adaxial e de quatro camadas na oposta. Mergulhados no parênquima fundamental, notam-se de cinco a sete feixes vasculares colaterais, de formato ovalado, envoltos por bainha esclerenquimática incompleta e dispostos em arco aberto (Figuras 2C, 2D). Os feixes maiores são também circundados por bainha amilífera e têm nítida zona cambial. Os elementos traqueais estão alinhados e separados por células parenquimáticas. Na nervura central e no mesofilo, encontram-se pequenos cristais de oxalato de cálcio na forma de drusas e cristais romboédricos.

\section{Anatomia caulinar}

Seccionado transversalmente, o caule exibe forma circular. Em estrutura secundária inicial, é revestido pela epiderme, que consiste de um estrato único de células (Figuras 3C, 3E), alongadas tangencialmente, recobertas por cutícula delgada e ornamentada por estrias evidentes. Estão presentes vários tricomas tectores (Figura 3A) e alguns glandulares similares aos da folha.

No córtex (Figuras 3B, 3C, 3E), junto ao sistema de revestimento, é encontrada uma faixa praticamente contínua de colênquima anelar, esparsamente alternada com cordões de clorênquima (Figura 3E). Segue-se o parênquima cortical multiestratificado, com células isodiamétricas, de paredes delgadas, contendo poucos cloroplastos e formando meatos. Limitando internamente a região cortical, observa-se uma endoderme (Figura 3C) com estrias de Caspary.

No cilindro vascular (Figuras 3B, 3C), o câmbio forma floema em direção à periferia e xilema de modo centrípeto, sendo mais ativo em direção ao xilema. Este se constitui de um cilindro completo, totalmente lignificado, associado a cordões de floema, aos quais calotas esclerenquimáticas estão apostas (Figuras 3C, 3D). A medula é formada de células parenquimáticas isodiamétricas e ocupa considerável volume caulinar. Pequenas drusas e cristais romboédricos de oxalato de cálcio ocorrem na região medular e no córtex.

\section{DISCUSSÃO}

\section{Folha}

Com relação à superfície foliar, consideramse o aspecto cuticular (Metcalfe \& Chalk, 1988) e a deposição de cera (Esau, 1974; Cutter, 1986; Fahn, 1990) caracteres diagnósticos importantes, E. mollis apresenta cutícula estriada, contudo sem revelar a presença de cera epicuticular. Esta, segundo Mauseth (1988), é de ocorrência universal sobre a parede periclinal externa das células epidérmicas. Para Barthlott et al. (1998), a deposição de cera ocorre geralmente na forma de finas películas e raramente como camadas mais espessas ou projeções. Quando as coberturas são muito finas, compondo-se de poucas camadas de moléculas, a visualização em microscopia eletrônica de varredura torna-se difícil na opinião desses últimos autores, o que pode justificar a inobservância de cera neste trabalho.

Tricomas também são utilizados com finalidades taxonômicas (Metcalfe \& Chalk, 1988) e na morfodiagnose de drogas vegetais (Oliveira \& Akisue, 1997). Segundo Oliveira et al. (2000), tricomas glandulares inseridos em depressão epidérmica, com pedicelo curto e glândula capitada, pluricelular e bisseriada são típicos das Asteraceae. $\mathrm{Na}$ pesquisa realizada por Castro et al. (1997), foi relatada a ocorrência de vários tipos de tricomas secretores em folhas de representantes de Asteraceae, incluindo-se Elephantopus biflorus (Less.) Sch. Bip., E. elongatus Gardn. e E. micropappus Less., e tal descrição vai ao encontro do resultado obtido para E. mollis. Na mesma investigação, não se constataram estruturas secretoras internas nas espécies de Elephantopus estudadas, em concordância com a presente análise.

Os tricomas glandulares bisseriados de E. mollis são semelhantes aos encontrados em plantas medicinais do táxon, como Artemisia nova A. Nelson (Kelsey \& Shafizadeh, 1980), Mikania cordifolia (L.f.) Willd. (Oliveira et al., 2000), M. glomerata Spreng. (Neves \& Sá, 1991), Santolina leucantha Bertol. (Pagni \& Masini, 1999), Stevia rebaudiana (Bert.) Bert. (Monteiro et al., 2001) e Tanacetum parthenium (L.) Sch. Bip. (Simmons et al., 2002). Na folha de E. mollis, Alquini e Bona (1995) identificaram a presença de tais tricomas somente na face abaxial, diferindo deste estudo, onde os mesmos foram encontrados em ambas as superfícies epidérmicas.

Aos tricomas glandulares, bem como aos tectores, são atribuídas diversas funções em comum, como contribuição à regulação da temperatura do vegetal e à reflexão luminosa, incluindo radiação ultravioleta, barreira ao deslocamento de insetos na superfície, redução da perda de água e orientação de polinizadores (Wagner et al., 2004). Da mesma forma que os tricomas glandulares, os tectores podem ser encontrados em diferentes órgãos vegetais e representam elementos morfológicos importantes, em razão da sua diversidade (Werker, 2000). A descrição dos tricomas tectores de $E$. mollis por Alquini e Bona (1995) foi corroborada nesta investigação e esses apêndices epidérmicos assemelhamse aos de Vernonia condensata Baker (Barreto et al., 1994).

Em Asteraceae, geralmente os estômatos 

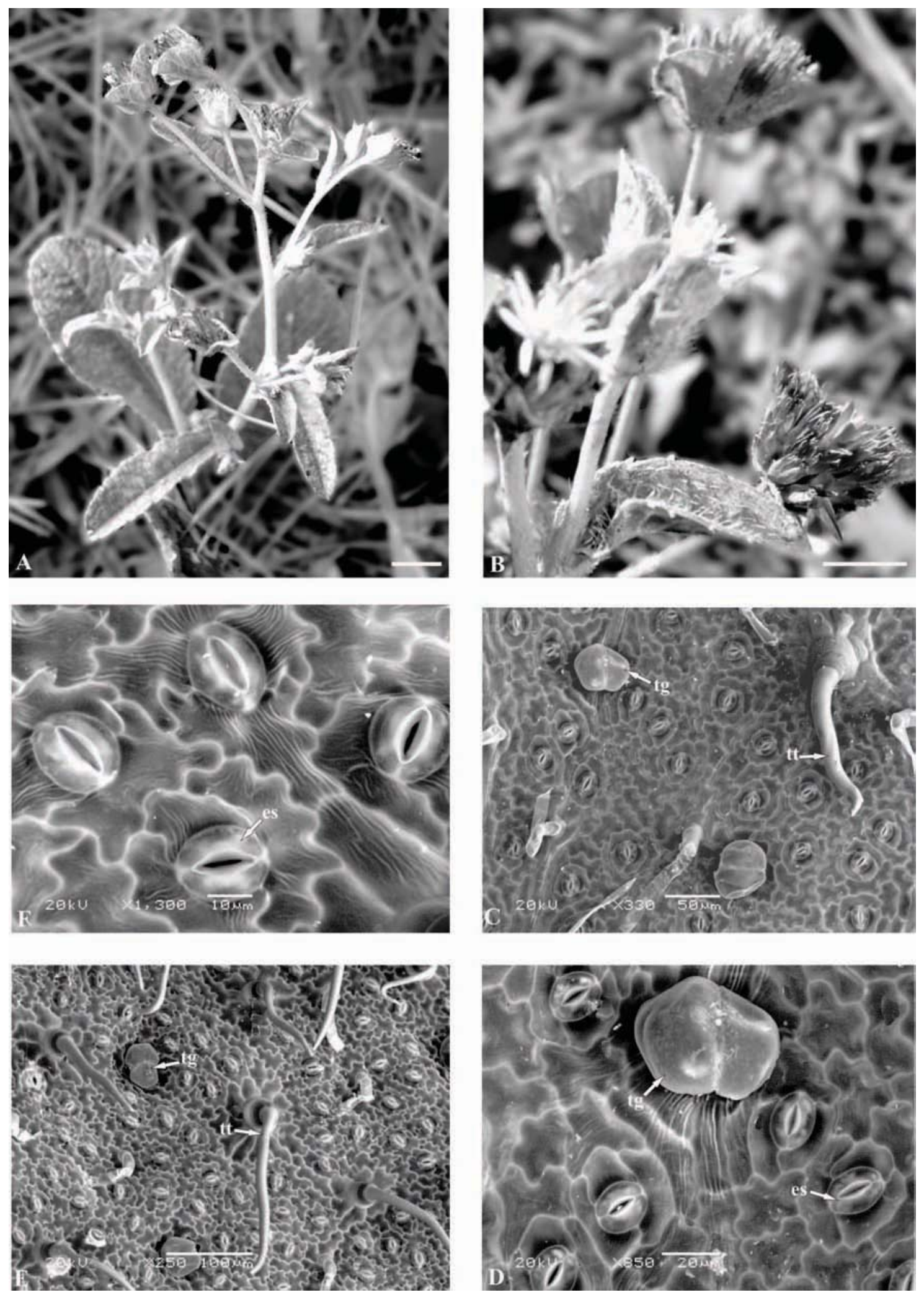

Figura 1. Elephantopus mollis Kunth: A. aspecto geral; B. detalhe das inflorescências; C, D. vista frontal da face adaxial da epiderme foliar (MEV); E, F. vista frontal da face abaxial da epiderme foliar (MEV). es - estômato, tg - tricoma glandular capitado, $\mathrm{tt}$ - tricoma tector. Barra $=2 \mathrm{~cm}(\mathrm{~A}, \mathrm{~B})$. 


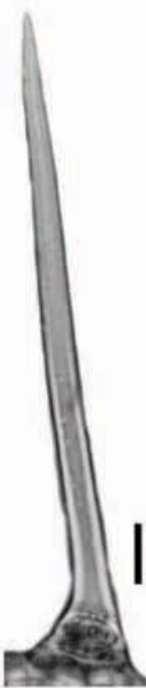

A
B
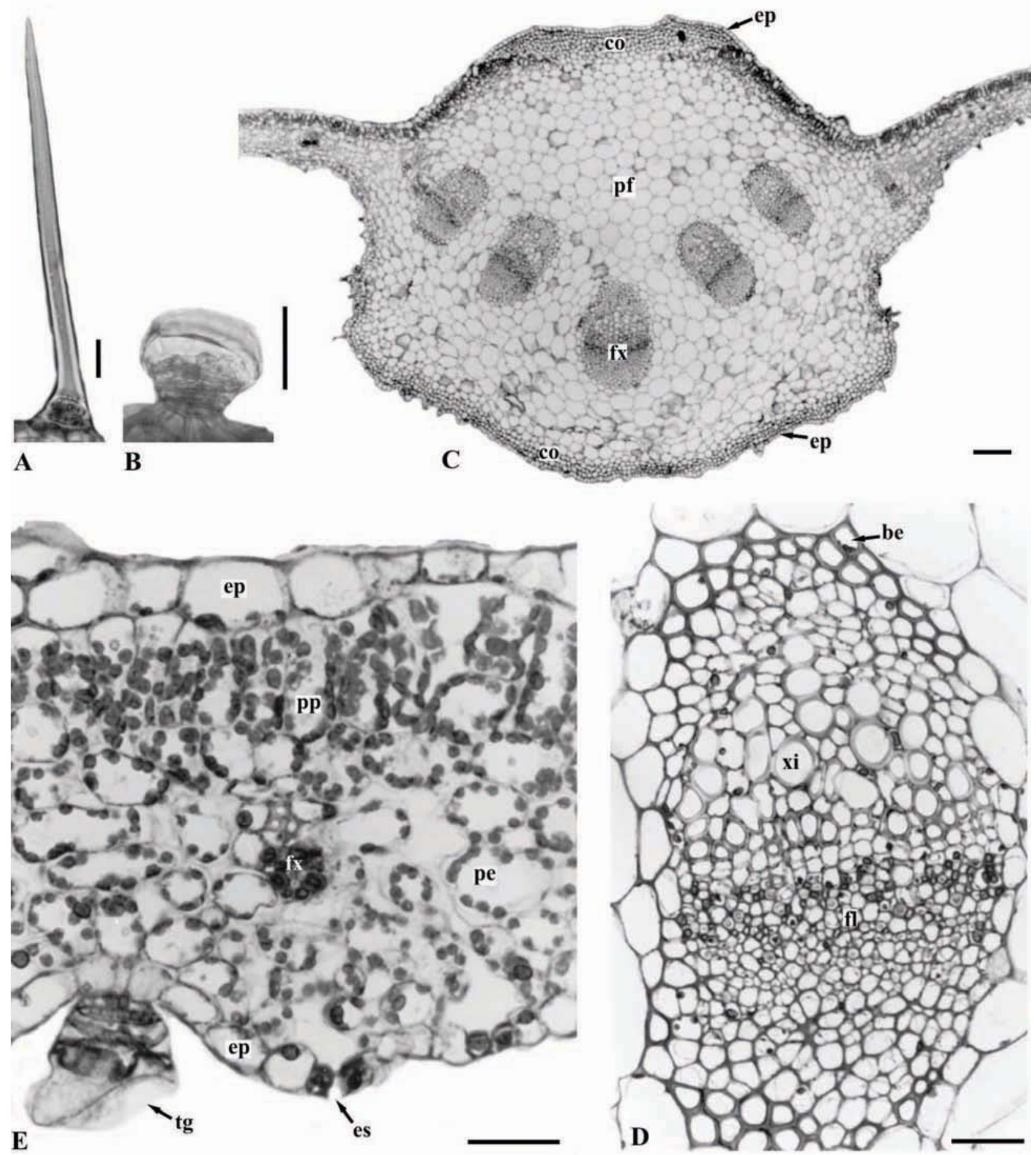

Figura 2. Elephantopus mollis Kunth - folha: A. tricoma tector; B. tricoma glandular capitado; C. secção transversal da nervura central; D. pormenor de um feixe vascular colateral na nervura central, envolto por bainha esclerenquimática incompleta; E. secção transversal da lâmina foliar, revelando mesofilo dorsiventral. be - bainha esclerenquimática, ep - epiderme, es - estômato, $\mathrm{fl}$ - floema, fx - feixe vascular, pe - parênquima esponjoso, pf - parênquima fundamental, pp - parênquima paliçádico, tg - tricoma glandular capitado, xi - xilema. Barra $=20 \mu \mathrm{m}(\mathrm{A}, \mathrm{B}, \mathrm{D}, \mathrm{E}), 100 \mu \mathrm{m}(\mathrm{C})$. 

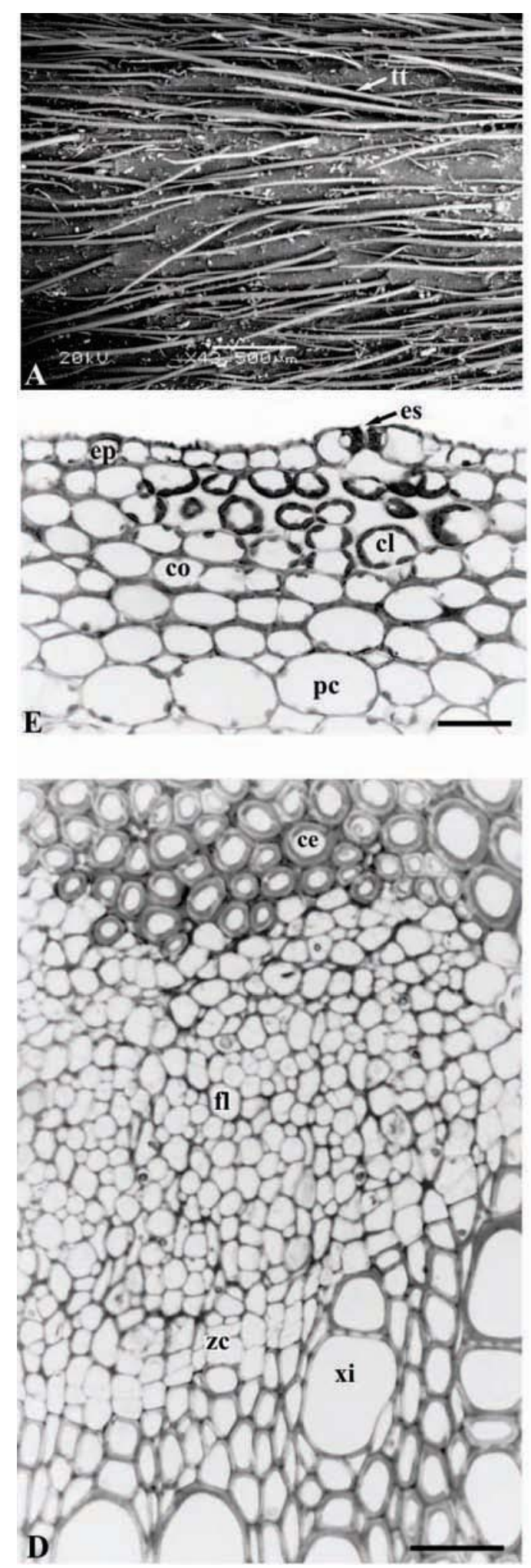
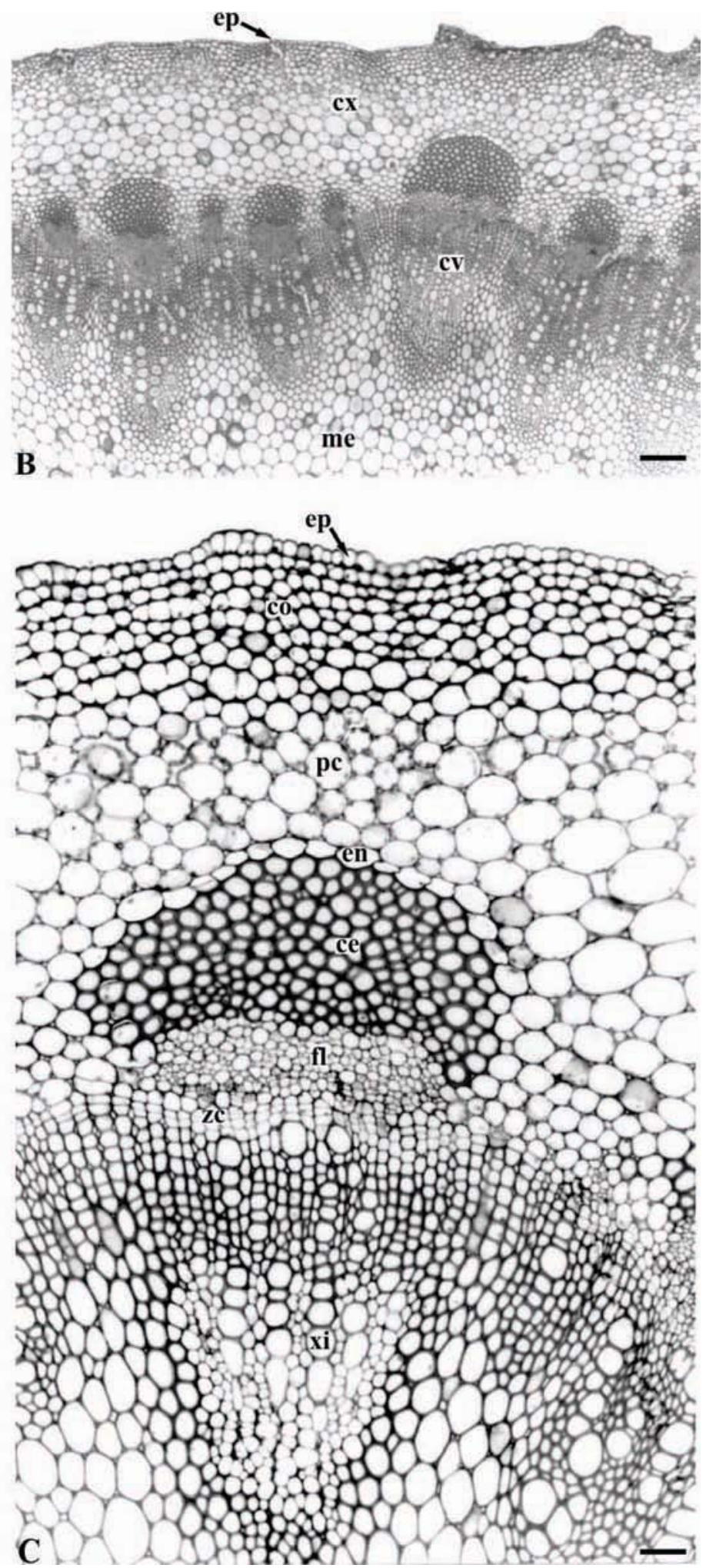

Figura 3. Elephantopus mollis Kunth - caule: A. vista frontal da epiderme caulinar, mostrando numerosos tricomas tectores (MEV); B, C. organização geral caulinar; D. detalhe do sistema vascular; E. pormenor do sistema de revestimento e de parte do córtex. ce - calota esclerenquimática, cl - clorênquima, co - colênquima, cv - cilindro vascular, cx - córtex, en - endoderme, ep - epiderme, $\mathrm{fl}$ - floema, me - medula, pc - parênquima cortical, $\mathrm{tt}$ - tricoma tector, xi - xilema, zc - zona cambial. Barra $=20 \mu \mathrm{m}(\mathrm{C}-\mathrm{E}), 100 \mu \mathrm{m}$ (B). 
são anomocíticos e anisocíticos, com predominância do primeiro tipo (Metcalfe \& Chalk, 1950), e podem ocorrer em ambas as faces epidérmicas, principalmente na abaxial, sendo as folhas classificadas como anfiestomáticas (Esau, 1974). Adicionalmente, mesofilo dorsiventral é considerado o padrão usual para a família (Metcalfe \& Chalk, 1950). Em conformidade com esses autores, na espécie em estudo as folhas possuem estômatos anomocíticos e anisocíticos predominantemente na superfície abaxial e o mesofilo é dorsiventral. Características semelhantes são encontradas em outras Asteraceae medicinais, como Ageratum conyzoides L. (Ferreira et al., 2002), Bidens pilosa L. (Duarte \& Estelita, 1999; Ferreira et al., 2002), Conyza bonariensis (L.) Cronquist (Procópio et al., 2003), Mikania conferta Gardn. (Oliveira et al., 1999), M. cordifolia (Oliveira et al., 2000), Taraxacum officinale Weber (Alquini \& Takemori, 2000), V. condensata (Barreto et al.,1994), Calea uniflora (Budel et al., 2006) e .Acanthospermum australe (Martins et al., 2006).

Com referência ao relato de pequenos cristais de oxalato de cálcio, a exemplo de $V$. condensata (Barreto et al., 1994) e E. mollis nesta investigação, a formação destes é comum nos vegetais, embora a freqüência diferencial responda a mudanças na concentração do íon metálico no meio ambiente (Nakata, 2003). A função que desempenham é variada e inclui regulação de cálcio nos tecidos, equilíbrio iônico, proteção contra herbivoria, suporte tecidual e detoxificação metálica (Franceschi \& Horner-Jr., 1980).

\section{Caule}

A epiderme caulinar é persistente em algumas Asteraceae (Metcalfe \& Chalk, 1950), como verificado no caule de E. mollis e em outras espécies medicinais do táxon, tais como Baccharis cylindrica (Less.) DC. (Budel et al., 2003a), B. dracunculifolia DC. (Budel et al., 2004), B. gaudichaudiana DC. (Budel et al., 2003b) e Lychnophora passerina (Mart. ex DC.) Gardn. (Luque \& Menezes, 2003).

$\mathrm{Na}$ família, a endoderme é bem definida, mostrando-se com uma fita de suberina ao redor das células, denominada de estria de Caspary, ou como bainha amilífera (Metcalfe \& Chalk, 1950). A endoderme típica é restrita a caules aéreos de algumas ervas e a caules subterrâneos (Fahn, 1990) e representa um caráter diagnóstico importante, visto que é menos freqüente em caule do que em raiz (Van Fleet, 1961; Mauseth, 1988). De modo similar a diferentes representantes de Asteraceae que possuem endoderme com estrias de Caspary no caule (Esau, 1974; Melo-de-Pinna \& Menezes, 2002), reconhece-se esse tipo de barreira em E. mollis. Plantas medicinais como B. pilosa (Duarte \& Estelita, 1999), M. conferta (Oliveira et al., 1999), M. cordifolia (Oliveira et al., 2000) e M. glomerata (Neves \& Sá, 1991) apresentam a mesma característica. Segundo
Pagni \& Masini (1999), em vários representantes de Asteraceae a endoderme está associada à presença de dutos secretores. Em Elephantopus, apesar do registro de dutos em raízes, os mesmos não são mencionados em caules (Lersten \&Curtis, 1987), sendo a ausência dessa estrutura secretora confirmada nesta análise.

$\mathrm{Na}$ espécie em questão, o caule apresenta o sistema condutor em arranjo padrão para a família, não se observando floema interno como relatado em determinadas Asteraceae (Metcalfe \& Chalk, 1950; Fahn, 1990). A título de comparação com algumas plantas medicinais da família, floema formado externamente ao xilema, com calotas de esclerênquima apostas ao sistema floemático, caracteriza a organização vascular do caule de E. mollis, bem como de B. dracunculifolia (Budel et al., 2004) e B. pilosa (Duarte \& Estelita, 1999), do mesmo modo que do eixo dos cladódios de $B$. cylindrica (Budel et al., 2003a), B. gaudichaudiana (Budel et al., 2003b) e B. trimera (Less.) DC. (Jorge et al., 1991).

\section{CONCLUSÃO}

Os caracteres estruturais de E. mollis correspondem aos descritos para Asteraceae e, embora devam ser avaliados em conjunto para caracterizar a espécie, alguns aspectos podem ser destacados: estômatos anomocíticos e anisocíticos predominantemente na superfície abaxial, mesofilo dorsiventral com clorênquimas pouco diferenciados e nervura central biconvexa e levemente achatada junto à face adaxial na folha; endoderme com estrias de Caspary e calotas esclerenquimáticas apostas ao floema no caule; pequenas drusas e cristais romboédricos de oxalato de cálcio, tricomas tectores pluricelulares e unisseriados, com célula apical proporcionalmente alongada, e tricomas glandulares capitados e bisseriados na folha e no caule.

\section{AGRADECIMENTOS}

Os autores expressam o seu reconhecimento aos taxonomistas do Museu Botânico Municipal de Curitiba pela identificação da espécie e ao Centro de Microscopia Eletrônica da UFPR pelas eletromicrografias de varredura.

\section{REFERÊNCIAS}

Alquini Y, Bona C 1995. Morfoanatomia dos tricomas foliares de Elephantopus mollis H.B.K. (Asteraceae), Oxipetalum panosum Decne. (Asclepiadaceae) e Luhea divaricata Mart. (Tiliaceae). Arq Biol Tecnol Curitiba 38: 1287-1293.

Alquini Y, Takemori NK 2000 Organização estrutural de espécies vegetais de interesse farmacológico. Curitiba: Herbarium. 
Banerjee S, Schmeda-Hirschmann G, Castro V, Schuster A, Jakupovic J, Bohlmann F 1986. Further sesquiterpene lactones from Elephantopus mollis and Centratherum punctatum. Planta Med 1: 29-32.

Barreto MA, Alves VFG, Neves LJ 1994. Contribuição ao estudo de Vernonia condensata Baker. Rev Bras Farm 75: 54-58.

Barroso GM 1991. Sistemática de angiospermas do Brasil. Viçosa: Universitária. v. 3.

Barthlott W, Neinhuis C, Cutler D, Ditsch F, Meusel I, Theisen I, Wilhelmi H 1998. Classification and terminology of plant epicuticular waxes. Bot J Linn Soc 129: 237-260.

Berlyn GP, Miksche JP 1976 Botanical microtechnique and cytochemistry. Ames: Iowa State University.

Biavatti MW, Marensi V, Leite SN, Reis A 2007. Ethnopharmacognostic survey on botanical compendia for potential cosmeceutic species from Atlantic Forest. Rev Bras Farmacogn 17: 640-653.

Budel JM, Duarte MR, Santos CAM 2003a. Stem morphoanatomy of Baccharis cylindrica (Less.) DC., Asteraceae. Rev Bras Cien Farm 40: 93-99.

Budel JM, Duarte MR, Santos CAM 2003b. Caracteres morfoanatômicos de Baccharis gaudichaudiana DC., Asteraceae. Acta Farm Bonaerense 22: 313-320.

Budel JM, Duarte MR, Santos CAM, Farago PV 2004. Morfoanatomia foliar e caulinar de Baccharis dracunculifolia DC., Asteraceae. Acta Farm Bonaerense 23: 477-483.

Budel JM, Duarte MR, Farago PV, Takeda IJM 2006. Caracteres anatômicos de folha e caule de Calea unifl ora Less., Asteraceae. Rev Bras Farmacogn 16: 53-60.

Brüning J 2000. A saúde brota da natureza. 18. ed. Curitiba: Expoente.

But PPH, Hon PM, Cao H, Che CT 1996. A new sesquiterpene lactone from Elephantopus mollis. Planta Med 62: 474-476.

Cabrera AL, Klein RM 1980. Compostas 3. Tribo: Vernonieae. Fl Ilust Catarinense 227-403.

Castro MM, Leitão-Filho HF, Monteiro WR 1997. The use of secretory structures for identification of genera of Asteraceae from cerrado vegetation. Rev Bras Bot 20: 163-174.

Corrêa MP 1984. Dicionário das plantas úteis do Brasil e das exóticas cultivadas. Rio de Janeiro: Nacional. v. 4.

Cutter EG 1986. Anatomia vegetal: células e tecidos. 2. ed. São Paulo: Roca.

Duarte MR, Estelita MEM 1999. Caracteres anatômicos de Bidens pilosa L., Asteraceae. Hoehnea 26: 15-27.

Esau K 1974. Anatomia das plantas com sementes. São Paulo: E. Blücher.

Fahn A 1990. Plant anatomy. 4. ed. Oxford: Pergamon.

Ferreira EA, Procópio SO, Silva AA, Rufino RJN 2002. Estudos anatômicos de folhas de espécies de plantas daninhas. II - Bidens pilosa, Emilia sonchifolia, Ageratum conyzoides e Sonchus asper. Planta
Daninha 20: 327-335.

Foster AS 1949. Practical plant anatomy. 2. ed. Princeton: D. Van Nostrand.

Franceschi VR, Horner-Jr HT 1980. Calcium oxalate crystals in plants. Bot Rev 46: 361-427.

Fuchino H, Koide T, Takahashi M, Sekita S, Satake M 2001. New sesquiterpene lactones from Elephantopus mollis and their leishmanicidal activities. Planta Med 67: 647-653.

Johansen DA 1940. Plant microtechnique. New York: McGraw-Hill Book.

Jorge LIF, Pereira U, Silva AM 1991. Identificação histológica das principais compostas brasileiras de emprego medicinal. Rev Inst Adolfo Lutz 51: 47-51.

Kelsey RG, Shafizadeh F 1980. Glandular trichomes and sesquiterpene lactones of Artemisia nova (Asteraceae). Biochem Syst Ecol 8: 371-378.

Kraus JE, Arduin M 1997. Manual básico de métodos em morfologia vegetal. Seropédica: Edur.

Lee KH, Ibuka T, Huang HC, Harris DL 1975. Antitumor agents 14: Molephantinin, a new potent antitumor sesquiterpene lactone from Elephantopus mollis. $J$ Pharm Sci 64: 1077-1078.

Lee KH, Ibuka T, Furukawa H, Kozuka M, Wu RY, Hall IH, Huang HC 1980. Antitumor agents 38: Isolation and structural elucidation of novel germacranolides and triterpenes from Elephantopus mollis. J Pharm Sci 69: 1050-1056.

Lersten NR, Curtis JD 1987. Internal secretory spaces in Asteraceae. A review and original observations on Conyza canadensis (Tribe Astereae). Cellule 74: 181-196.

Lin CC, Yen MH, Chiu HF 1991. The pharmacological and pathological studies on Taiwan folk medicine (VI): The effects of Elephantopus scaber subsp. oblanceolata, E. mollis and Pseudoelephantopus spicatus. Am J Chin Med 19: 41-50.

Lin CC, Tsai CC, Yen MH 1995. The evaluation of hepatoprotective effects of Taiwan folk medicine "Teng-Khia-U”. J Ethnopharmacol 45: 113-123.

Lorenzi H, Matos FJA 2002. Plantas medicinais no Brasil: nativas e exóticas. Nova Odessa: Plantarum.

Luque R, Menezes NL 2003. Estructura primaria del tallo de Lychnophora Mart. (Vernonieae: Asteraceae). Plantula 3: 117-128.

Martins LRR, Mourão KSM, Albiero ALM, Cortez DAG, Dias-Filho BP, Nakamura CV 2006. Estudo morfoanatômico preliminar do caule e da folha de Acanthospermum australe (Loefl.) Kuntze (Asteraceae-Heliantheae). Rev Bras Farmacogn 16: 42-52.

Mauseth JD 1988. Plant anatomy. Menlo Park: Benjamin/ Cummings.

Melo-de-Pinna GFA, Menezes NL 2002. Vegetative organ of Ianthopappus corymbosus Roque \& Hind (Asteraceae-Mutisieae). Rev Bras Bot 25: 505-514.

Metcalfe CR, Chalk L 1950. Anatomy of dicotyledons: leaves, 
stem, and woods in relation to taxonomy with notes on economic uses. Oxford: Clarendon. v. 2.

Metcalfe CR, Chalk L 1988. Anatomy of dicotyledons. Oxford: Clarendon. v. 1.

Monteiro WR, Castro MM, Viveiros SCM, Mahlberg PG 2001. Development and some histochemical aspects of foliar glandular trichomes of Stevia rebaudiana (Bert.) Bert. - Asteraceae. Rev Bras Bot 24: 349-357.

Nakata PA 2003. Advances in our understanding of calcium oxalate crystal formation and function in plants. Plant Sci 164: 901-909.

Neves LJ, Sá MFA 1991. Contribuição ao estudo das plantas medicinais Mikania glomerata Spreng. Rev Bras Farm 72: 42-47.

O’Brien TP, Feder N, McCully ME 1964. Polychromatic staining of plant cell walls by toluidine blue $\mathrm{O}$. Protoplasma 59: 368-373.

Oliveira F, Akisue G 1997. Fundamentos de farmacobotânica. 2. ed. São Paulo: Atheneu.

Oliveira F, Rodrigues RFO, Kato ETM 1999. Estudo farmacognóstico da almécega-da-praia - Mikania conferta Gardn. Lecta 17: 43-68.

Oliveira F, Rodrigues RFO, Bastos DHM, Pereira FH 2000. Caracterização morfohistológica e verificação da atividade microbiológica da espécie vegetal Mikania cordifolia (Lf.) Willd. Lecta 18: 33-63.

Pagni AM, Masini A 1999. Morphology, distribution, and histochemistry of secretory structures in vegetative organs of Santolina leucantha Bertol. (Asteraceae). Isr J Plant Sci 49: 257-263.

Procópio SO, Ferreira EA, Silva EAM, Silva AA, Rufino RJN, Santos JB 2003. Estudos anatômicos de folhas de espécies de plantas daninhas de grande ocorrência no Brasil. III - Galinsoga parviflora, Crotalaria incana, Conyza bonariensis e Ipomoea cairica. Planta Daninha 21: 1-9.

Roeser KR 1972. Die Nadel der Schwarzkiefer-Massenprodukt und Kunstwerk der Natur. Mikrokosmos 61: 33-36.

Sass JE 1951. Botanical microtechnique. 2. ed. Ames: Iowa State College.

Simmons CB, Krishna-Raj S, Saxena PK 2002. Morphocytological characterization of feverfew, Tanacetum parthenium (L.) Schultz Bip. J Herbs Spices Med Plants 9: 29-45.

Souza W 1998. Técnicas básicas de microscopia eletrônica aplicadas às Ciências Biológicas. Rio de Janeiro: Sociedade Brasileira de Microscopia Eletrônica.

Takeda IJM, Farago PV 2001. Vegetação do Parque Estadual de Vila Velha: guia de campo. Curitiba: Serzegraf. v. 1.

Tsai CC, Lin CC 1999. Anti-inflammatory effects of Taiwan folk medicine "Teng-Khia-U" on carrageenan and adjuvant-induced paw edema in rats. $J$ Ethnopharmacol 64: 85-89.

Van Fleet DS 1961. Histochemistry and function of the endodermis. Bot Rev 27: 165-220.
Wagner GJ, Wang E, Shepherd RW 2004. New approaches for studying and exploiting an old protuberance, the plant trichome. Ann Bot 93: 3-11.

Werker E 2000. Trichome diversity and development. Adv Bot Res 31: 1-35. 